\title{
Lugares de memoria en El palacio de la risa de Germán Marín y Nocturno de Chile de Roberto Bolaño Places of Memory in El palacio de la risa by Germán Marín and Nocturno de Chile by Roberto Bolaño
}

\author{
Bieke Willem \\ Universiteit Gent \\ Bieke.Willem@ugent.be
}

\begin{abstract}
Este trabajo explora la manera en que Germán Marín y Roberto Bolaño reconstruyen el mismo lieu de mémoire chileno, a saber, la casa privada que fue utilizada durante la dictadura como centro de detención y tortura. Una comparación entre por un lado la arquitectura de un lugar de memoria "real", el Parque por la Paz Villa Grimaldi, y por otro lado, las casas evocadas en El palacio de la risa de Marín y Nocturno de Chile de Bolaño, revela la importancia de la nostalgia y de lo siniestro. Estas dos emociones permiten a los autores narrar lo inenarrable, y al mismo tiempo echar una mirada crítica sobre el pasado reciente y el presente postdictatorial.
\end{abstract}

Palabras clave: Lugar de memoria, nostalgia, lo siniestro.

This article explores the way in which Germán Marín and Roberto Bolaño reconstruct the same Chilean lieu de mémoire: the private house that was used as a torture house during the military dictatorship. A comparison between the architecture of a 'real' place of memory, Parque por la Paz Villa Grimaldi, and the houses that Bolaño and Marín reconstructed in words, reveals the importance of nostalgia and the uncanny. These two emotions allow the authors to say the unsayable, and to adopt a critical attitude towards the recent past and the postdictatorial present.

Keywords: Place of Memory, Nostalgia, the Uncanny. 


\section{Villa Grimaldi: lugar de memoria}

El núcleo del debate postdictatorial lo constituye el paradigma de la memoria, un tema extremadamente delicado en sociedades que se encuentran todavía divididas a pesar de las evidencias de crueldades cometidas en un pasado no tan remoto. ¿Cómo evitar la banalización de estas crueldades? ¿Cómo narrarlas a las generaciones que vienen después? ¿Cómo evitar que esto ocurra de nuevo? ¿Cómo asegurarnos un futuro sin por un lado olvidar el pasado pero sin que, por otro lado, este pasado llegue a dominar el presente? Son algunas de las preguntas que surgieron después de las atrocidades de la Segunda Guerra Mundial, y que vuelven a surgir después de cada período de crisis en Europa, África, América Latina, junto con la pregunta sobre el papel del arte en este proceso. O como lo formula Idelber Avelar en la versión inglesa de su Alegorías de la derrota: Can literature still play any role in this memonic and political task? (The Untimely Present 2). Según Avelar, la literatura puede todavía desempeñar un papel cuando es mnemónica. Es precisamente el deber del intelectual de la oposición (lea: izquierdista), de ir en contra de la lógica del mercado que "pretende pensar el pasado en una operación sustitutiva sin restos" (Alegorías 14). Debe al contrario revelar los residuos, las ruinas "que pueden activar la irrupción intempestiva del pasado en el presente" (Alegorías 286).

El objetivo de este artículo es examinar la manera en que Roberto Bolaño y Germán Marín cumplen con su deber mnemónico mediante la reconstrucción ficcional de un terreno arruinado por la dictadura chilena. Ambos autores sitúan (una parte de) su narración en una casa privada que ha sido utilizada como centro de detención y tortura en los años 70.

Pero antes de centrarnos en la ficción, visitaremos primero una de estas ruinas de piedra. Villa Grimaldi es vista como la ruina icónica de la violencia dictatorial, y más en particular de esas casas privadas que fueron utilizadas como lugares de tortura. Entre 1973 y 1979, cuando el recinto llevaba el nombre de Cuartel Terranova, 4.500 personas fueron torturadas ahí, de las cuales 226 nunca regresaron a casa.

Después de la dictadura, la Corporación Parque por la Paz emprendió la misión de llevar la memoria hacia la ciudad y a la sociedad chilena en general. En 1994, los vecinos, familiares de detenidos-desaparecidos y sobrevivientes de Villa Grimaldi lograron abrir el recinto al público. De la antigua casona ya no quedaba nada después de que el terreno fue vendido primero a un familiar de un general del ejército chileno para construir ahí un complejo habitacional. Pero a partir de los escombros, unos años más tarde, la arquitecta Ana Cristina Torrealba diseñó un parque que constituyera un "símbolo de reflexión, encuentro y referente para la memoria, la justicia y la promoción de los Derechos Humanos"1. En el sitio web y en las publicaciones de la Corporación se presenta claramente el parque como un "lugar de memoria", definido por Pierre Nora como unité significative, d'ordre matériel ou

1 Fuente: sitio web de la Corporación Parque por la Paz: "Parque por la paz" (www. villagrimaldi.cl) 
idéel, dont la volonté des hommes ou le travail du temps a fait un élément symbolique d'une quelconque communauté (1004).

A pesar del incontestable valor simbólico de Villa Grimaldi, Michael J. Lazzara califica el antiguo centro de tortura como un no-lugar, remitiendo a un spot publicitario en la Televisión Nacional sobre el parque en el que no se dice palabra de los horrores ocurridos ahí sino que se insiste en la tranquilidad y en la belleza del nuevo diseño (Prismas 212). Aparentemente, Lazzara no es el único para quien resulta problemática la asociación de la belleza con los acontecimientos terroríficos que ocurrieron en lo que son ahora "lugares de memoria". Para muchos críticos, las flores, las fuentes y los mosaicos llenos de colores del Parque por la Paz banalizan el lugar donde se mutilaban los cuerpos de los detenidos con vehículos o donde se hacía entrar ratas en la vagina de las mujeres para interrogarlas. Según la Crítica de la memoria efectuada por Nelly Richard, los mosaicos en el suelo que describen someramente estos sucesos representan una memoria "apaciguada":

[...] una memoria que cultiva el embellecimiento de las ruinas del parque para fabricar un mensaje de vida y esperanza que intenta revertir el pasado de muerte pero que, al hacerlo decorativamente, vuelve completamente inofensiva la recordación de lo abyecto cuya mención no logra actualizarse en nada dramáticamente acusatorio (256).

Pero no solo es la decoración de un pasado traumático la que, a pesar de los esfuerzos de los iniciadores del proyecto Villa Grimaldi para difundir la memoria mediante manifestaciones culturales y el desarrollo de material didáctico, impide una memoria "activa", en el sentido de una memoria vivida descrita por Andreas Huyssen². Eso se puede explicar parcialmente por rasgos intrínsecos del terreno. Como antigua finca, históricamente ya es un lugar aislado, cerca de la cordillera y alejado del centro. Ahora la ciudad se ha expandido, de modo que el Parque por la Paz se encuentra rodeado ya de los barrios de viviendas de la clase media de Peñalolén. Sin embargo hay poca interacción con el afuera. Con la instauración del Parque en los años 90 decidieron conservar el aspecto exterior del campo de detención. Los gruesos muros de adobe y el portalón de hierro con la mirilla son los únicos elementos siniestros que quedan sobre el terreno. Podrían responder a las exigencias de Nelly Richard de que un lugar que representa los recuerdos de la dictadura militar debiera reproducir la sensación de encierro, pero al mismo tiempo impiden que el lugar pueda ser calificado como un espacio público. Michael J. Lazzara señala la magra presencia de visitantes chilenos al terreno, y su estatus de lugar remoto y semiolvidado en el mapa santiaguino. Añade que "cada vez que h[a] estado en Villa Grimaldi, [le] ha parecido un lugar fantasmal, un lugar donde se preservan las ruinas del pasado, pero en el que prácticamente no hay personas para permitir su actualización o llevar a cabo el trabajo de la memoria" (Prismas, 210-211).

2 "La memoria vivida es activa: tiene vida, está encarnada en lo social [...] Esas son las memorias necesarias para construir los diferentes futuros locales en un mundo global" (Huyssen, En busca 39). 
Lo que las comunidades hacen con las ruinas de un pasado oscuro -optar por la demolición, o, al contrario, la reconstrucción (selectiva) o la resignificación de un terreno- revela mucho sobre la posición que esta comunidad toma frente al pasado y se incluye en la política de una época. El Parque por la Paz Villa Grimaldi es un caso emblemático porque fue el primer centro de detención y tortura recuperado por las víctimas y sus familiares. En aquel entonces, la reconstrucción de la memoria en estos lugares no hacía parte en absoluto de las prioridades del joven Estado democrático. Sin embargo, guiado por el Informe Rettig publicado en 1991, el primer gobierno de la Concertación hacía esfuerzos para valorar la reconciliación y la reparación, lo que se traduce en el diseño del Parque por la Paz. No se trata de una reconstrucción del espacio que albergue una memoria traumática, sino, como se nota en los discursos pronunciados durante su inauguración, de una resignificación, de una connotación positiva. Carlos Gho, el entonces presidente de la Corporación Parque por la Paz Villa Grimaldi, anunció que "en este lugar, donde en otro tiempo los señores de la muerte cometieron crímenes bestiales y negaron todos los derechos a sus prisioneros, hoy florecerá la vida" (Lazzara, Prismas 215).

Pero como acabamos de ver, esta resignificación ha suscitado serias críticas acerca del diseño del dolor. Surgieron además narraciones alternativas a partir de esas mismas ruinas que escondían los recuerdos de la represión dictatorial. En Nocturno de Chile (2000) y El palacio de la risa (2008, primera versión en 1995), sus respectivos autores Roberto Bolaño y Germán Marín escriben contra la corriente de reconciliación, olvido y consenso, característica de los años noventa en Chile. En el caso de El palacio de la risa, el texto consiste en una reconstrucción literaria del espacio de Villa Grimaldi, antes y después de que adquirió la triste fama de centro clandestino de tortura. En unas 130 páginas, sirviéndose de un realismo minucioso, el narrador cuenta de lo que para él personalmente 3 significa el espacio nombrado. Ordena las descripciones de la casa temporalmente según tres etapas en su vida que se entremezclan a medida que la narración va avanzando. Nos lleva primero a su infancia, durante la que pasó algunos veranos felices en la casa de su amigo Antonio cuando esta aún no llevaba el nombre de Villa Grimaldi. Luego nos guía, junto con su amante Mónica, por la casa convertida en discoteca "El Paraíso" en vísperas del golpe de Estado, y finalmente, cuando regresa del exilio, nos muestra los escombros en los que queda convertida la casona después de la larga dictadura de Pinochet.

Bolaño sitúa una parte importante de su novela Nocturno de Chile en la casa de María Canales, disfraz de Mariana Callejas, cuentista y novelista pero también durante algún tiempo agente de la DINA, que colaboró con su esposo Michael Vernon Townley en el asesinato de Carlos Prats en Buenos Aires y Orlando Letelier en Washington. En su casa de tres pisos en Lo Curro, uno de los barrios más exclusivos de Santiago situado en los faldeos de la cordillera, Callejas combinaba una vida familiar con la organización de talleres

3 Sin que por ello el narrador y el autor de la novela coincidan, podemos considerar El palacio de la risa como un texto autobiográfico. Ciertas indicaciones, como el exilio en Barcelona, el título del libro que está escribiendo el narrador-protagonista (Carne de perro), y las personas a las que frecuenta permiten identificar al yo de la novela con Germán Marín. 
literarios mientras que su esposo se ocupaba del cuartel de la DINA instalado en esta misma casa. En la novela de Bolaño, el protagonista Sebastián Urrutia Lacroix, seudónimo de José Miguel Ibáñez Langlois, prácticamente el único crítico literario durante el régimen de Pinochet, nos confiesa sus visitas a esta casa.

La arquitectura memorial, brevemente comentado al inicio de este trabajo, y la literatura desempeñan básicamente la misma función: la de representar, en este caso, un pasado oscuro. Las preguntas claves, tanto para la arquitectura como para la literatura, son entonces siempre las siguientes: ¿Cómo representar? ¿Mediante qué "diseño"? Y sobre todo: ¿Qué historia hay que narrar? En lo que sigue examinaremos la manera en que Bolaño y Marín se enfrentan a estas preguntas. Sin considerar sus novelas como meras versiones literarias de los espacios físicos, podemos utilizar los mismos parámetros que nos fueron útiles en el momento de comentar el Parque por la Paz para un análisis literario de la reconstrucción de los lugares de memoria en ambas novelas. Así, el criterio de la oposición e interacción entre dentro y fuera sirve también para determinar la función de la casa de tortura en los textos literarios, y la manera en que se narra este espacio.

\section{Dentro y fuera}

Ambos autores subrayan el carácter aislado de la casa visitada por sus protagonistas. El narrador de El palacio de la risa compara varias veces el terreno en Peñalolén, este "mundo cerrado a pesar de su extensión (30), con una "isla" (30), separado de Santiago por el canal San Carlos. La dictadura refuerza aun este aspecto cerrado, ya que se añaden corridas de alambre sobre los gruesos muros de adobe, y un portalón de hierro con una mirilla. Cuando el narrador visita el baldío en el que queda convertida la Villa Grimaldi después de la dictadura, el encierro le provoca una profunda sensación de angustia. El terreno "se [viera] menos vasto, apretado por las murallas lindantes, como así también el horizonte, cerrado por la presencia inmediata de la cordillera que parecía más cercana que ayer" (18). Además, parece que el terreno se encuentra bajo una campana de cristal, tan fuerte es el contraste entre el silencio que reina entre los muros de adobe y el ruido del mundo exterior ${ }^{4}$.

La casa de María Canales, descrita por Roberto Bolaño en Nocturno de Chile, también se ubica aislada, en las afueras de la ciudad. Él insiste sin embargo en el hecho de que, contrariamente a la Villa Grimaldi, durante los años de la dictadura militar mantenía todavía su aspecto exterior de una vivienda de familia. En esta ambigüedad reside el núcleo del horror incluido en estas casas privadas donde se aplicaba la tortura: la convivencia de la violencia más inconcebible con una tranquila vida cotidiana.

4 El narrador de El palacio de la risa insiste varias veces en el silencio que reina dentro del recinto. Podemos relacionarlo a la "ley del silencio, una suerte de omertá o pacto de sangre entre los uniformados" (Marín, 119), que debería ocultar la ubicación de los centros de tortura. 
En el texto de Marín, el narrador cuenta cómo los prisioneros en Villa Grimaldi lograban adivinar la hora mediante los ruidos que vienen desde afuera. El canto de los pájaros, las campanadas de una iglesia cercana y el bullicio del recreo, grabados en la memoria de los sobrevivientes, ayudaba también a los colaboradores de la Vicaría de la Solidaridad a ubicar el centro después de la dictadura. Lo que al narrador le asombra es sobre todo que:

[...] El Palacio de la Risa hubiera existido, no, coexistido, en aquel barrio amable que lo rodeaba lleno de esperadas casitas de tejas rojas, bendecidas por las campanadas de la iglesia vecina, donde como suponía era posible toparse con unas señoras jóvenes bien arregladas, coquetas, que iban de compras a los pequeños negocios de alimentos cercanos y con unos niños en vacaciones de verano que, al caer la tarde, salían a dar vueltas a la manzana en bicicleta (85-86).

Y concluye con amargura: "Así parecía ser en su ambigüedad el país que estaba conociendo, si es que no había sido siempre igual" (86). La convivencia de estos dos mundos, característica típica de Chile en esa época, se resume en una imagen clave de la novela. En la escena en que una muchacha en bikini toma el sol al lado de la piscina que en esos tiempos ya fue utilizada como lugar de tortura, convergen el pasado feliz de la mansión y la tremenda realidad del campo de detención; la tortura y la vida cotidiana; el horror y la belleza.

Lo único que la asombrara [a una exprisionera] era que cierta mañana, al pasar ante la piscina camino a un interrogatorio en el garaje en desuso de la casona, pudo ver, al resbalarse la venda que cubría sus ojos, a una muchacha en bikini tendida en el césped cuyo rostro, a pesar de llevar unos lentes oscuros de marcos blancos, le pareció de sumo familiar. Abstraída de cuanto sucedía alrededor, tomaba el sol acostada sobre una toalla de baño. A su lado dormitaba Diablo hecho un ovillo, un doberman de color negro bastante feroz que, junto con otro mastín, había adiestrado para dicho campo una oficial de Carabineros Ilamada Ingrid, experta en el entrenamiento de animales (80).

Los dos mundos se entretejen no solo en este tipo de imágenes (pensamos por ejemplo también en el contraste entre las rosas salvajes y los palquis que huelen a muerte), sino también en la propia escritura, de una manera no siempre tan armoniosa. En las dos primeras partes, el narrador nos transmite información histórica sobre el pasado glorioso de la mansión, cuando fue frecuentada por, entre otros, José Victorino Lastarria, Andrés Bello, Benjamín Vicuña Mackenna, Ignacio Domeyko, José Manuel Balmaceda, Lorenzo Sazié, y más tarde también por el crítico literario Alone. A eso se añaden sus recuerdos de infancia, de los cuales los más felices están relacionados con la casa de su amigo Antonio. Entre estos datos que envuelven la mansión y el parque en Peñalolén en un aura de felicidad brota el horror 
bajo la forma de frases repentinas que mencionan fríamente la función que desempeñaban los diferentes aposentos del Cuartel Terranova. Mediante esta brusca yuxtaposición de largas frases poéticas rememorando los olores del parque, la luz que se filtraba entre sus hojas, la música de cámara que llenaba siempre la mansión, y la casi científica precisión y frialdad con que menciona la despensa, la torre de agua, el sótano, donde se practicaba la "Pau de Arara" u otros métodos de tortura, el autor logra captar el núcleo de sentido encerrado en el recinto de Villa Grimaldi: que en medio de la tranquilidad y la belleza de una casona donde vivía una familia feliz, puede surgir la crueldad más inconcebible.

La misma idea forma la base de la construcción literaria que Roberto Bolaño hace a partir de la casa de Mariana Callejas ${ }^{5}$. Como Marín, Roberto Bolaño se basa en un edificio que ha existido realmente, pero mientras el primero no se cansa de describir los detalles de lo que antes fue la mansión en Peñalolén, Bolaño despoja la casa de Mariana Callejas de todos sus atributos hasta que solo se queda con una estructura básica: dos partes que se sobreponen. Arriba, los escritores, músicos y críticos de arte se entregan a discusiones literarias y otros placeres más terrenales porque en el Chile del toque de queda no encuentran otro lugar para reunirse.

Los escritores (y los críticos) no teníamos muchos lugares adonde ir. María Canales tenía una casa en las afueras. Una casa grande, rodeada por un jardín lleno de árboles, una casa con una sala confortable, con chimenea y buen whisky, buen coñac, una casa abierta para los amigos una vez a la semana, dos veces a la semana, en raras ocasiones tres veces a la semana (125).

Como el negativo de estas escenas calurosas, abajo, en la oscuridad del sótano, se llevan a cabo sesiones de tortura ${ }^{6}$. La música y las risas de arriba sofocan los gritos de espanto de abajo. Y los visitantes de la casa lo saben, pero nadie dice nada. Así, el arte y la literatura se revelan como máscaras del horror. Mediante la construcción encima/debajo de la casa de María Canales, Bolaño no solo sugiere, como lo indica Adriana Castillo-Berchenko, "las otras caras de la dominación y el desenfreno del autoritarismo, la superioridad y arbitrariedad de los vencedores; la inferioridad de los vencidos" (38), sino que formula también una tremenda crítica a esos intelectuales chilenos (como el crítico literario José Miguel Ibáñez Langlois) que se mostraban indiferentes a lo que estaba ocurriendo en el país. Muestra que en el Chile de Pinochet lo bello pudiera convivir con lo perverso, sin que nadie en este círculo de "privilegiados" levantara la voz.

\footnotetext{
5 Bolaño no fue el primero en ficcionalizar la casa de Mariana Callejas. Como lo apunta en "El pasillo sin salida aparente", un texto publicado en una revista española en 1999 y más tarde incluido en el volumen Entre Paréntesis, Pedro Lemebel lo precedió con la crónica "Las orquídeas negras de Mariana Callejas". Además, la propia escritora escribió en sus memorias sobre su casa y cómo fue utilizada tanto para reuniones artísticas como para sesiones de tortura.

6 Es significativo que Bolaño desplace al sótano las sesiones de tortura que en la realidad tenían lugar en el primer piso.
} 
Lo que hace la imagen de la casa de María Canales tan impactante, es que no solo revela la simbiosis que la perversión mantiene con el arte, sino también, como nos indica la escena de la muchacha en bikini en la novela de Marín, con la cotidianeidad. Dentro de la estricta estructura encima/debajo de la casa de María Canales, algunos escasos detalles - un sillón en el rincón del salón, un jarrón con flores, la chimenea- dotan al lugar de domesticidad. Además, no es una casualidad que el narrador presenta primero a María Canales como mujer, y luego como escritora ("Había una mujer. Se llamaba María Canales. Era escritora, era buena moza, era joven" (124). La protección maternal y afectividad femenina hacen de esta casa un verdadero refugio, un "castillo hospitalario" (128) para la élite del mundo artístico chileno. Al fin y al cabo, esta casa en las afueras de Santiago es ante todo una casa de familia. En repetidas ocasiones, la anfitriona deja bajar a sus niños al salón para saludar a los invitados.

\section{Lo siniestro}

Al final de la novela, Bolaño aprovecha tres ocasiones para perturbar esta burbuja de intimidad familiar. Tres veces, el narrador cuenta cómo alguien de la compañía se pierde en los pasillos que llevan al sótano, encuentra el cuerpo de un hombre medio vivo atado a una cama metálica, y vuelve a la fiesta sin avisar a nadie. Si en los dos últimos asedios el escritor se centra sobre todo en el encuentro con el cuerpo "aún vivo", en la primera versión dedica más atención al vacilante recorrido por los pasillos y cuartos que el visitante efectúa hasta llegar a la cámara de tormento:

En vez de tomar el pasillo a la derecha, tomó el de la izquierda, luego se metió por otro pasillo, bajó unas escaleras, estaba en el sótano y no se dio cuenta, la casa, en verdad, era muy grande: un crucigrama. El caso es que anduvo por diversos corredores y abrió puertas, y encontró muchas habitaciones vacías u ocupadas por cajas de embalaje o por grandes telarañas que la mapuche no se tomaba la molestia de limpiar jamás. Finalmente llegó a un pasillo más estrecho que todos los demás y abrió la última puerta (138-139).

El viejo motivo del "descenso a los infiernos" es actualizado aquí mediante el principio arquitectónico del enfilade, una hilera de puertas típica del estilo barroco. Encontramos esta construcción ya en episodios anteriores; pensamos en particular en la historia del zapatero que tiene que traspasar una infinita fila de puertas y recámaras antes de llegar a su imperador ${ }^{7}$, y en el encuentro de Salvador Reyes con el escritor alemán Ernst Jünger ${ }^{8}$. Cada uno

\footnotetext{
7 "Y cuando hubo movido todas las palancas empezaron a abrirse las puertas y el zapatero traspuso umbrales y antesalas e ingresó en salones cada vez más majestuosos y oscuros, aunque de una oscuridad satinada, una oscuridad regia, en donde las pisadas no resonaban, [...], y en la última cámara a la que fue conducido estaba sentado en una silla de lo más corriente el Emperador [...] (Bolaño 2000: 53-54).

8 "Y don Salvador [...] dijo que sí, que encantado, preséntemelo no más, Giovanna, y la italiana, la duquesa o condesa italiana que tan bien quería a nuestro escritor y diplomático,
} 
de estos recorridos nos llevan a una imagen clave que revela la perversión del poder. Estas dos historias pueden a su vez ser vistas como un trayecto de cámaras en fila hacia el núcleo de sentido contenido en la casa de María Canales: el hombre desnudo atado de las muñecas y de los tobillos al catre metálico, descrito tres veces, y cada vez con más insistencia en el dolor, cada vez más escatológico ${ }^{9}$.

El movimiento del descenso y después la construcción en enfilade, técnicas probadas en las películas de terror, se utilizan aquí para crear suspense y envolver la historia definitivamente en lo siniestro, que ya flota en todas las páginas precedentes de la novela bajo la forma de los fantasmas del protagonista. Mediante la transición del piso de arriba a la oscuridad del sótano se pasa a otro nivel, pero se queda básicamente en el mismo espacio: el de la casa. Aquí asistimos a una hipertrofia de lo que Freud denominaba Unheimlich: la sensación de extrañeza, angustia y malestar provocada por la proximidad de lo familiar y lo que es totalmente su contrario ${ }^{10}$. En el término que utiliza Freud, todavía encontramos la raíz que nos redirige al hogar (heim), lo que desaparece por completo en la traducción al español: lo siniestro. Con la construcción literaria de la casa de María Canales, Bolaño logra agarrar este origen de no-hogar y ofrecernos una condensación de lo siniestro que, como lo señala también Ricardo Cuadros, es una categoría inherente a su escritura:

Maestro del claroscuro (con más tendencia al oscuro, claro está) Bolaño escoge en su escritura los intersticios donde aguarda lo siniestro, pero a diferencia de E. A. Poe o del Conde de Lautréamont, que inventaban escenarios y personajes truculentos, Bolaño habla de lo siniestro que flota a plena luz del día, más aún, lo siniestro como parte integral, inseparable de la historia no entendida como texto oficial sino como experiencia cotidiana (86).

En la descripción detallada de la mansión en Peñalolén, antes y después de que fue utilizada como Cuartel Terranova, Germán Marín también otorga un lugar central a lo siniestro. El ambiente que reina en el terreno convertido en ruina, cuando el narrador lo visita después de la dictadura, es amenazante por la presencia demasiado cerca de la cordillera, por el silencio que reina dentro del recinto, por la cegadora luminosidad del sol de diciembre, y porque

lo guió a través de varios salones, cada salón se abría a otro salón, como rosas místicas, y en el último salón había un grupo de oficiales de la Wehrmacht y varios civiles y el centro de atención de toda esta gente era el capitán Jünger, el héroe de la Primera Guerra Mundial [...]" (Bolaño 2000: 38).

9 Este descenso a los infiernos culmina en la imagen final de la novela cuando "la verdad empieza a ascender como un cadáver" (149) y "se desata la tormenta de mierda" (150).

10 Aunque centrado sobre todo en la arquitectura contemporánea, el estudio de Anthony Vidler, The Architectural Uncanny: Essays in the Modern Unhomely, propone reflexiones acerca del concepto freudiano de Unheimlich que son también particularmente interesantes para un estudio del espacio literario. Vidler demuestra la relación esencial entre por un lado esta sensación de malestar que primero fue tematizada en los cuentos de, entre otros, Hoffman y Poe, y más tarde psicologizada por Freud, y el espacio por otro lado, donde se manifiesta sobre todo en el campo de fuerzas entre dentro y fuera. 
lo poco que queda -algunos trozos de cimiento, un árbol petrificado- apunta hacia la muerte y la desaparición. Todo eso, como hemos visto, se vuelve aún más siniestro por el contraste con los ruidos cotidianos que vienen del exterior. En los episodios en que el protagonista visita junto con su amante Mónica la casa convertida en discoteca en vísperas del golpe de estado, el escritor explota más esta categoría de lo siniestro. La oscuridad, la música fantasmal que vuelve del pasado glorioso cuando se organizaban conciertos de cámara, y las "estatuas ensimismadas en las sombras" (68) del parque confieren a la casa el aspecto de un castillo de la literatura gótica. Al mismo tiempo sin embargo, las breves frases que indican el cambio de funciones de los diferentes aposentos en tanto casa, discoteca y cuartel, añaden algo más escalofriante y real a esta imagen. Cuando el narrador rememora en el exilio sus visitas a la casa, admite que ha proseguido "impoluta [...], libre de terrores" (49-50), pero añade inmediatamente que "[le] acosaba sin expresarse, velada por diversos subterfugios oníricos, cierta inquietud lindante con la angustia" (50). Es precisamente esta misma sensación que Freud ha relacionado con lo siniestro.

\section{La nostalgia}

Lo que predomina sin embargo durante su exilio, es la nostalgia (de nostos -volver a casa, y algia- deseo) de un pasado feliz contenido en las piedras de la antigua Villa Grimaldi.

Como me viene a la memoria de aquella estación, al caminar en el parque bajo el viento perfumado que emanaba de la Avenida de los Tilos, sentía el olor de las hojas quemadas por Mañunco, el jardinero [...]. La fragancia de aquellas tardes, mezcla de flores vivas y de restos invernales, no se borraría de mí hasta el grado de que en Barcelona, durante el exilio, más de una vez desperté anhelante en la madrugada, desorientado en la oscuridad, llamado en el sueño por esa vocación. Qué cantidades de errores justos provoca la nostalgia (49).

La añoranza del esplendor de la casona y su parque es una proyección de la nostalgia que siente el narrador-escritor por el Chile que dejó al marcharse al extranjero. Cuando vuelve del exilio y contempla "la pesadez corrupta e indecible de la basura", consta que este germen de felicidad y protección que se encontraba en la casa de su infancia ha desaparecido irremediablemente. Solo le queda preguntarse con amargura:

[...] a qué país había llegado hacía dos meses, pues, aunque lo deseara, este ya no parecía ser el mío luego de pasar por la verdad de esa mañana. Era hoy otro país como trataba de decirme, distinto al que había dejado al marchar al extranjero, ajeno como cualquiera de los que había pisado durante diecisiete años (50).

El narrador de El palacio de la risa ilustra aquí una observación que Svetlana Boym hace en su obra sobre la nostalgia: de que este nostos, que anhelamos tanto, en realidad no existe o nunca ha existido. "Nostalgia", escribe Boym, 
is a longing for a home that no longer exists or has never existed. Nostalgia is a sentiment of loss and displacement, but it is also a romance with one's own fantasy (XIII). De ahí que, guiado por la nostalgia, el narrador intente reconstruir una vez más el esplendor de aquella mansión de la infancia, no en la realidad, porque se da cuenta de su desaparición definitiva, sino en la literatura. Sabe que la nostalgia deformará irremediablemente la casa reconstruida mediante palabras, pero no la considera necesariamente como algo negativo. Solamente provoca "errores justos".

En Nocturno de Chile es más difícil detectar este duelo originado por una casa perdida (lee: una dicha perdida) que llamamos nostalgia. Pero como ya indica el título de Nocturno de Chile ${ }^{11}$, la novela está impregnada de melancolía, una sensación lindante con la nostalgia ${ }^{12}$. Stephanie Decante y Karim Benmiloud oponen la melancolía "esnob" del protagonista H. Ibacache a la melancolía mórbida del pintor guatemalteco. La primera sería una pose intelectual, una imitación del artista del fin del siglo, y por ende una manifestación del tópico de la separación entre el arte y la vida. Decante señala que esta separación es simbolizada de manera espacial en las casas de los letrados Farewell y Canales, que son representadas como "lugares de repliegue, cortados de la realidad política cotidiana" (20, mi traducción). Sin embargo, como acabamos de ver, la casa de María Canales resulta mostrar al mismo tiempo la inquietante proximidad entre el mundo político y el de los artes. La misteriosa enfermedad de la que sufre el pintor guatemalteco es una reacción a esa perversa consanguinidad del arte y el mal. Es, según Decante, una melancolía que podemos relacionar "al dolor de lo indecible frente al horror" (23, mi traducción). El cuadro titulado Paisaje de Ciudad de México una hora antes del amanecer, pintado por el guatemalteco durante su residencia en París, revela los lazos entre la melancolía, la memoria y la representación fragmentaria. De esta manera, "la melancolía", en las palabras de Decante, "se convertiría en un lugar de exploración de una práctica artística (de una poética) llevada por una ética justificada frente a la memoria" (31, mi traducción).

La nostalgia es tradicionalmente considerada como el lado kitsch de la memoria, como una postura frente al pasado en la que falta esta dimensión "ética" de la que habla Decante. Como ha observado Boym, por lo general se considera la nostalgia como an abdication of personal responsibility, a guilt-free homecoming, an ethical and aesthetic failure (XIV). El discurso del protagonista de Nocturno de Chile se caracteriza precisamente por el empeño de esquivar la responsabilidad de sus actos, y sobre todo de sus silencios. "Mis silencios son inmaculados" (Bolaño 11-12), dice al inicio de su confesión

11 El Diccionario de la Real Academia Española define nocturno no solamente como "Pieza de música vocal o instrumental, de melodía dulce, propia para recordar los sentimientos apacibles de una noche tranquila", sino que también señala su uso como adjetivo aplicable a un hombre: "Que anda siempre solo, melancólico y triste".

12 Freud ha elaborado una clara distinción entre duelo y melancolía. La melancolía es la reacción patológica a la pérdida de un ser amado o una abstracción, mientras que el duelo es la reacción "normal", que permite un cierre con el pasado (Rouw en melancholie). Boym ha profundizado la diferencia entre melancolía y nostalgia. Una de sus conclusiones es que la última emoción está más cerca de la memoria colectiva (XVI), a lo que volveremos más lejos. 
que se asemeja más a una justificación. Sin embargo, es precisamente por no haber dicho nada cuando supo del secreto del sótano de la casa de María Canales que se hizo cómplice del régimen dictatorial, junto con los otros intelectuales allí presentes. A su fracaso como poeta se suma entonces una derrota ética, en contradicción con su misión de cura.

¿Es entonces la nostalgia la que lleva, después de la dictadura, a Sebastián Urrutia Lacroix a visitar de nuevo la casa de María Canales? Durante la visita el cura no se puede contener en comparar el esplendor del pasado con la decrepitud del presente: "La casa ya no parecía la misma: todo su esplendor, un esplendor nocturno e impune, había desaparecido" (143). Sin embargo, la casa "postdictatorial" no difiere tanto de la de los años 70. Ha conservado los mismos signos externos que la definían al mismo tiempo como una casa de familia ("una bicicleta infantil, de color rojo, estaba tirada junto a las escaleras de acceso al porche" (143)), y un centro clandestino de tortura ("la maleza [...] trepando por las rejas como si quisiera velar al paseante ocasional la visión del interior de aquella casa marcada" (143)). Urrutia Lacroix sigue en lo posible evitando ver este segundo aspecto de la casa de María Canales: las sesiones de tortura deben permanecer en su memoria como "escenas incomprensibles" y "lejanas" (143). No pueden concretizarse; por eso se niega a ver el sótano, a pesar de que María Canales se lo propone repetidas veces.

La tenacidad con la que ella se aferra a su antiguo castillo hospitalario ("Ya no tenía amigos, ni dinero, su marido la había olvidado a ella y a sus hijos, todo el mundo le había dado la espalda, pero ella seguía allí" (144)) muestra rasgos de una demencia en ciernes, pero sobre todo de una nostalgia por las veladas de antaño, cuando aún le permitieron hablar de literatura en vez de política. Su actitud ilustra también la inmoralidad que se adscribe generalmente a la nostalgia: cuando María Canales lamenta que de su casa "no quedará memoria alguna" (145), refiere -con un perverso sensacionalismo- tanto a la gloriosa como a la oscura memoria recluida en el sótano.

Urrutia Lacroix y María Canales encarnan aquí una nostalgia estereotipada, conservadora. Citando a Denilson Lopes, Avelar la contrasta con la más "noble" melancolía, y la define de la manera siguiente:

[...] la nostalgia, claramente fijada en un objeto, idealizando el pasado, [...] se diferenciaría claramente de la melancolía, que ha acumulado un saber sobre la catástrofe que impide cualquier fijación nítida en la imagen de un pasado dichoso. [...] La melancolía se diferencia "de la nostalgia [...] al sospechar de las visiones positivas del futuro, con poco espacio para el presente e idealizadoras del pasado (Avelar, Nueva Sociedad 216).

Este contraste entre melancolía y nostalgia se asemeja a la diferencia que Boym establece entre dos tipos de nostalgia, a saber, la restaurativa y la reflexiva:

Restorative nostalgia stresses nostos and attempts a transhistorical reconstruction of the lost home. Reflective nostalgia thrives in algia, the longing itself, and delays 
the homecoming -wistfully, ironically, desperately. [...] Restorative nostalgia protects the absolute truth, while reflective nostalgia calls it into doubt (XVIII).

Mientras que Urrutia Lacroix y María Canales ejemplifican el primer tipo de nostalgia, el narrador de la novela de Marín se inclina más hacia la nostalgia reflexiva. Su vacilante investigación de la suerte de la casona y de su examante Mónica pone realmente en duda la existencia de una verdad sobre el pasado y muestra claramente la imposibilidad de agarrar la memoria. El escritor advierte, contrariamente a lo que su realismo a veces hace suponer, que se trata de "un ayer trabado por [su] propia mano" (Marín 127). Así, El palacio de la risa se presenta a pesar de la aparente intención historiográfica de "llegar a la verdad" como una de las posibles narraciones en torno a Villa Grimaldi, como la es también el diseño del Parque por la Paz.

Ya nos detuvimos brevemente en la fuerza creadora de la nostalgia del narrador de Marín. La nostalgia del pasado glorioso oculto en la ruina le incita a recrear este espacio en palabras. Afirma el potencial creativo de la nostalgia reflexiva, que, según Boym, reveals the fantasies of the age, and it is in those fantasies and potentialities that the future is born (351). Esto se acerca a la idea de la "melancolía creadora", ya mencionada por Aristóteles cuando sitúa esta emoción entre el genio y la demencia, lo que es más tarde desarrollado por Benjamin y Agamben ${ }^{13}$. De ahí viene también la idea de Avelar de que la literatura postdictatorial de alguna manera puede contener todavía la posibilidad de una redención:

Nutriéndose de un recuerdo enlutado que intenta superar el trauma ocasionado por las dictaduras, la literatura postdictatorial lleva consigo las semillas de una energía mesiánica que, como el ángel benjaminiano de la historia, mira hacia el pasado, a la pila de escombros, ruinas y derrotas, en un esfuerzo por redimirlos, mientras es empujado hacia adelante por las fuerzas del "progreso" y la modernización (Avelar, Alegorías 286).

A pesar de que Avelar relaciona este intento de redención al hecho de que "la literatura postdictatorial se encuentra [...] perennemente al borde de la melancolía" (Alegorías 315), preferimos aquí seguir utilizando el concepto de la nostalgia en vez de la melancolía. El apego a la casa -lo que Avelar llama "fetichismo" (Nueva Sociedad 216)- y el vínculo que la nostalgia permite establecer entre lo individual y lo colectivo ${ }^{14}$, justifican esta opción.

\footnotetext{
13 Véase las siguientes obras: Aristóteles. Over melancholie. Trans. Philip van der Eijk. Groningen: Historische uitgeverij, 2001. Benjamin, Walter. The origin of German Tragic Drama. 1928. Trans. John Osborne. London: Verso, 1985. Y Agamben, Giorgio. Stanze: Parole et fantasme dans la culture occidentale (1981). Paris, Payot et Rivages, coll. "Poches", 1998. 14 Véase Boym: Unlike melancholia, which confines itself to the planes of individual consciousness, nostalgia is about the relationship between individual biography and the biography of groups or nations, between personal and collective memory (XVI). Bolaño y Marín logran precisamente vincular la memoria individual con la colectiva mediante la evocación de las casas que fueron utilizadas como centros de tortura.
} 


\section{Las ruinas}

El lazo entre lo colectivo y lo individual no se limita a la memoria. En Nocturno de Chile y El palacio de la risa, los lugares de memoria no solo son presentados como imágenes ambiguas del pasado, sino también como muestras concretas de un presente postdictatorial. En ambas novelas, los autores muestran el presente de las casas de tortura bajo la forma de una ruina, un terreno en el que se puede efectuar una suerte de arqueología del presente.

Como acabamos de ver, la casa de María Canales en el fondo no ha cambiado tanto, pero el tiempo, y sobre todo la verdad que se reveló sobre la casa en el tiempo, la han convertido en una "casa marcada" (143), "condenada" (146), sucia, oscura, decrepitada, polvorienta. Incluso la habitante muestra señas de decadencia: se mueve con "cansancio y hastío [...]. Estaba más gorda que antes. Y vestía peor que antes" (144).

El detallismo con que se describe esta visita a la ruina en la que queda convertida la casa de María Canales contrasta con la sobriedad con la que Bolaño ha evocado la casa de los años de "esplendor". Esta vez se acerca más al realismo con que Marín reconstruye Villa Grimaldi en la ficción. Después de que fue demolida, y antes de la construcción del Parque por la Paz, prácticamente no queda nada del antiguo edificio, y sin embargo Marín logra describir este vacío con mucha atención por el detalle:

Lo que más abundaba en aquel yermo eran los palquis, fáciles de identificar por el nauseabundo olor de sus hojas lanceoladas, en que el tufo a muerte se mezclaba con la exudación mefítica de las cañerías de desagüe a ras del suelo. Se escuchaba en torno el zumbido gris de las moscas de verano (19).

Se nota aquí claramente que la evocación de la ruina se hace a partir de una construcción sinestética en la que predominan el oído y el olfato. Fueron precisamente estos sentidos los que sirvieron a los presos en los campos de detención, sometidos a "la nuda vida" (Agamben) ${ }^{15}$, a formarse una imagen del mundo que se desarrollaba detrás de la venda que "ayudaba, según las ideas de María del Carmen, a profundizar las aprensiones" (Marín 103). Ya que, después de la dictadura, sobre el terreno no quedan muchas huellas del pasado que se pueden percibir con los ojos, el oído y el olfato posibilitan el balanceo entre el pasado y el presente. Así, en el momento de despedirse del terreno baldío, el narrador cree oír la canción Siboney, lo que lo lleva a los días felices

\footnotetext{
15 Pensamos en los siguientes fragmentos de El palacio de la risa que muestran la importancia del oído y del olfato para los prisioneros: "El sistema de megafonía instalado en el aposento [...] no solo prestaba ayuda para requerir a uno otro personal de guardia, sino que también para sofocar los alaridos de la tortura mediante las canciones, repetidas hasta el infinito, interpretado por los Huasos Quincheros, Raphael, la Orquesta Huambalí" (Marín 103) y: "El olfato ayudaba a identificar a los demás, pero sobre todo a verificar el estado de sí mismo. Era un espejo empañado que servía para observar la miseria en que el cuerpo podía caer al ser sustraído de la costumbre diaria de la higiene" (Marín 110-112).
} 
que pasaba en la mansión cuando niño. El olor de las rosas lo vincula con los prisioneros para los que el perfume era una prueba de que la vida y la belleza perduraban en este lugar del horror. El contraste con los palquis que huelen a muerte revela otra vez el núcleo de sentido recluido en la Villa Grimaldi: la de la convivencia entre la vida normal, la belleza, y el horror.

La manera en la que Marín evoca el espacio a partir de las experiencias sensoriales hace pensar otra vez en las ruinas del romanticismo, que, como ha observado Masiello, awaken us to the sensorial realm (30). La clara separación entre dentro y fuera que comentamos al inicio del artículo actualiza los arcos, las rejas, los matorrales oscuros de la iconografía gótica y refuerza la sensación de entrar en otro mundo, a pesar de la escritura realista. Las detalladas descripciones sensoriales envuelven este mundo en una cobertura poética, casi armoniosa. Pero ya observamos que el discurso poético titubea cuando se refiere a los hechos que ocurrieron en el lugar durante la dictadura. Estos solo pueden ser representados mediante breves frases despojadas de cualquier poesía, o, en el caso de la novela de Bolaño, mediante una abstracción sugestiva.

Las ruinas evocadas por Marín y Bolaño comparten algunos rasgos de las de la literatura romántica, pero difieren en un punto esencial: la casa de María Canales después de la dictadura y el terreno baldío en el que queda convertida la Villa Grimaldi se muestran a plena luz del día. En Nocturno de Chile este hecho es notable porque como indica el título, la mayor parte de la novela sucede en un Santiago nocturno; las escenas memorables en la casa de María Canales tienen lugar durante el toque de queda. En El palacio de la risa Marín insiste en esa luz diurna, sinónima de la verdad: "La mañana de diciembre había alcanzado un dominio fugaz sobre el sitio eriazo, sujeto a ese momento de brillo y crueldad, ya que nada a su alrededor quedaba al margen de la luz reveladora" (Marín 85).

La luz revela sobre todo que casi no queda evidencia de las crueldades ocurridas durante la dictadura: el Cuartel Terranova ya ha sido demolido, y la casa de María Canales comparte el mismo destino. De esta manera los autores arrojan luz sobre la política de silencio, de "blanqueo" que caracterizó los años 90 según Tomás Moulián. Sus ruinas no solo revelan la dificultad de agarrar un pasado oscuro, sino que implican también una crítica del presente. Son una advertencia contra la desaparición de la memoria. Así, los lugares de memoria, representados primero como campos de tortura sobrepuestos sobre espacios de intimidad familiar y elitismo artístico y luego como ruina, funcionan claramente como metáforas del país, tanto bajo la dictadura como en el período postdictatorial.

\section{Conclusión}

Una visita virtual al "lugar de memoria" Parque por la Paz Villa Grimaldi nos mostró que, a pesar del intento de ir en contra de la desaparición definitiva, a veces resulta problemático el diseño de una memoria traumática. Las novelas de Roberto Bolaño y Germán Marín ofrecen narraciones paralelas sobre el estrecho lazo entre espacio y memoria sin incurrir en el embellecimiento ni en la representación de una memoria "única". Lo hacen mediante la 
insistencia en lo siniestro y la nostalgia, dos sensaciones que no se traducen tan fácilmente en un diseño arquitectónico de memorial.

Lo siniestro, que se puede entender como la sensación de angustia y malestar provocada por la proximidad de lo familiar y lo no-familiar, el horror, inserta las casas de tortura en una tradición de la literatura gótica y de las películas de suspense, lo que crea la distancia necesaria para narrar lo inenarrable. Al mismo tiempo, precisamente porque ambos autores insisten en la convivencia de lo familiar, lo bello, y lo que es totalmente su contrario, logran mostrar lo esencial del mal ocurrido durante la dictadura, y lo hacen más palpable.

La nostalgia, por su parte, tiene un lado obsceno, perverso, cuando es entendida como una posición frente al pasado que esquiva la responsabilidad. La relación que Urrutia Lacroix y María Canales mantienen con la casa de ella ilustran esta nostalgia "restaurativa". Por otro lado, la nostalgia reflexiva puede convertirse en una fuerza creadora y un posicionamiento crítico frente al pasado, presente y futuro. La nostalgia de la que cae presa el narrador de El palacio de la risa le ayuda finalmente a llevar a cabo la "investigación" sobre Villa Grimaldi, lo que ha resultado en la novela que acabamos de analizar.

En esta novela, Marín efectúa una minuciosa reconstrucción de la llamada Villa Grimaldi antes y después de la dictadura militar y de esta manera se opone manifiestamente a la política del blanqueamiento de los primeros años democráticos en Chile. Pero su versión tampoco concuerda con la resignificación a la que fue sometida el espacio físico al convertirlo en un Parque por la Paz. La memoria que está incluida en su Villa Grimaldi es plural, colectiva e individual, y tan vacilante que resulta imposible captarla en una sola imagen. En su mezcla de ensayo, memorias y novela, aunque dominada por la nostalgia, no encontramos ni un resquicio de esperanza, sino solo amargura por el estado en el que Chile se encuentra después de la dictadura. Además, aunque, como Roberto Merino lo observa en la contratapa, Marín "ostenta a veces la hiperestesia de un simbolista", evita el simbolismo liso de una "fuente de la vida" o un "árbol de la esperanza", artefactos que encontramos hoy en el parque.

Roberto Bolaño opera de una manera contraria para representar la memoria traumática relacionada a ciertos lugares en Santiago. Mientras que Marín individualiza los recuerdos y los presenta de una manera realista, Bolaño abstrae todas las casas privadas que fueron utilizadas como centros de tortura durante el régimen militar. La casa de María Canales, que consiste de la superposición de un espacio familiar y uno del horror, es al mismo tiempo una metáfora del país de aquel período y una crítica fulminante a los intelectuales chilenos que sabían lo que pasaba en la casa/Chile, pero que preferían guardar silencio.

Si es cierto que Bolaño y Marín difieren en la manera en la que representan el pasado, su evocación del presente de los lugares de memoria, en tanto ruinas, coincide. Sus novelas reafirman el carácter intermediario de las ruinas: la conexión entre pasado y presente, tiempo y espacio, memoria y nostalgia establecida mediante sus casas de tortura abre el espacio para 
una reflexión crítica sobre el pasado y el presente postdictatorial. "Narran las ruinas", lo que según Lazzara significa "imponer una arruinación transformativa y creativa sobre los objetos materiales de la historia" (Lazzara, Telling ruins 4, mi traducción).

\section{Obras citadas}

Aristoteles. Over melancholie. Trans. Philip van der Eijk. Groningen: Historische uitgeverij, 2001.

Avelar, Idelber. The Untimely Present. Postdictatorial Fiction and the Task of Mourning. Duke University Press, 1999.

Avelar, Idelber. Alegorías de la derrota: la ficción postdictatorial y el trabajo del duelo. Santiago: Cuarto Propio, 2000.

Avelar, Idelber. "Sensibilidad melancólica y alegoría crítica". Nueva Sociedad 170 (2000): 212-17.

Benmiloud, Karim. "Figures de la mélancolie dans Nocturno de Chile". Les astres noires de Roberto Bolaño. Eds. Karim Benmiloud and Raphaël Estève. Bordeaux: Université de Bordeaux, 2007. 109-34.

Bolaño, Roberto. Nocturno de Chile. Santiago: Anagrama, 2000.

Boym, Svetlana. The future of nostalgia. New York: Basic Books, 2001.

Castillo-Berchenko, Adriana. "Así se hace la literatura en Chile: María Canales en Nocturno de Chile". La memoria de la dictadura. Ed. Moreno Fernando. Paris: Ellipses, 2006.

Cuadros, Ricardo. "Lo siniestro en el aire". La memoria de la dictadura. Ed. Moreno Fernando. Paris: Ellipses, 2006.

Decante, Stéphanie. "Mémoire et mélancolie dans Nocturno de Chile: éléments pour une poétique du fragmentaire". Les astres noires de Roberto Bolaño. Eds. Karim Benmiloud and Raphaël Estève. Bordeaux: Université de Bordeaux, 2007. 11-32.

Freud, Sigmund. "Rouw en melancholie". Werken IV. Meppel: Boom, 2006. Huyssen, Andreas. En busca del futuro perdido. Cultura y memoria en tiempos de globalización. México D.F.: Fondo de Cultura Económica, 2002.

Lazzara, Michael J. Prismas de la memoria: narración y trauma en la transición chilena. Santiago: Editorial Cuarto Propio, 2007.

Lazzara, Michael J., and Vicky Unruh. "Introduction: Telling Ruins". Telling Ruins in Latin America. Eds. Michael J. Lazzara and Vicky Unruh. New York: Palgrave Macmillan, 2009. 1-9.

Marín, Germán. El palacio de la risa. Ed. Contemporánea. Santiago: Random House Mondadori, 2008.

Masiello, Francine. "Scribbling on the Wreck". Telling Ruins in Latin America. Eds. Michael J. Lazzara and Vicky Unruh. New York: Palgrave Macmillan, 2009. 27-38.

Nora, Pierre. "L'ère de la commémoration". Les lieux de mémoire. Ed. Pierre Nora. Vol. III. Les France 3. De I'archive à l'emblème. Paris: Gallimard, 1992. 974-1012.

Richard, Nelly. Crítica de la memoria. Santiago: Universidad Diego Portales, 2010.

Vidler, Anthony. The Architectural Uncanny: Essays in the Modern Unhomely. Cambrige, London: Massachusetts Institute of Technology, 1992. 